\title{
Design And Analysis Of Formula Sae Vehicle Rear Upright Andcomparision Of Analytical And Software Analysis Solutions Ofprincipelstressesat Differentpoints
}

\section{Sasanapuri Sandeep ${ }^{1}$,M. Lakshmi Sramika}

${ }^{1}$ M.Tech(CAD/CAM) Scholar Dept of Mechanical Engineering Avanthi Institute Of Engineering \& Technology ${ }^{2}$ Associate Professor Dept of Mechanical Engineering Avanthi Institute Of Engineering \& Technology Article History: Received: 11 January 2021; Accepted: 27 February 2021; Published online: 5 April 2021

\begin{abstract}
Upright is used in vehicles which connects frame or chassis and tires. Chassis is connected toupright with A-arms at the top and bottom using different types of fasteners through which theload is transmitted to it. I choose to design a FSAE(formula society of automobile engineers) caruprightbasedonthedatacollectedfromarealtimehybridformulavehicle.Uprightismodeledin Solidworks 2015 and all principle stresses and strains are found through simulation analysissoftware ANSYS 19.2. Now these solutions are compared with the analytical solutions which issolved using MATLAB software, So that we can be able to predict which one is more accurateandhowthese simulationsoftwareare beingableto solveproblemsbased ontheseconcepts.
\end{abstract}

\section{Introduction}

Amajorcomponentofthevehiclesuspensionsystemwhichnallowstheteeringarmtoturnthefrontwheelsandsupportt heverticalloadofthevehicle.Itisalsoknownas knuckle. upright is one which connects steering arms, control arms, springs, brake calipers,tires and incase rear upright then it also connects axles as shown in fig.1. It provides adjustmentof different suspension parameters like steering Ackerman geometry, caster, camber and scrubradius [1]. The forces encountered by the car due to road and tire interactions go through upright,so the upright should be stiff and strong to withstand high forces. Also be able to withstandfailure at the time of crashing or other emergencies because the failure of upright makes the carun-drivable. Car upright is subjected to fatigue load, braking force, cornering force, impact loadduringits servicelife [2].Theuprightorknuckledesigndeterminesthegeometryonthesuspension's"outboard"side.(The mounting points on the chassis and wishbones / links form the "inboard" side of the suspensionand make their owncontributionto the overallgeometryofthe suspension.)

The fig.1 illustrates an example of a non - driven independent wishbone suspension. The upright(Yellow) is attached to the car using the upper and lower wishbones which have fasteners (balljointsorrodends).Thisallowstheuprighttorotateaboutthekingpinaxisandmovevertically.

Part attached to the upright is the spindle(green). Bearings (Orange) are inserted into the hub(Red) and it is slide over the spindle and held in place by a retaining nut. The brake disc (Blue)placed over the Threaded bolts extending from the hub. The brake caliper (Light blue) is attachedusinga bracket to upright.

The steering angle of the upright can be set using the steering/toe link which has a rod end thatfastensusingballjointto an arm(Purple) ontheupright. 


\section{Non-Driven Wheel Upright}

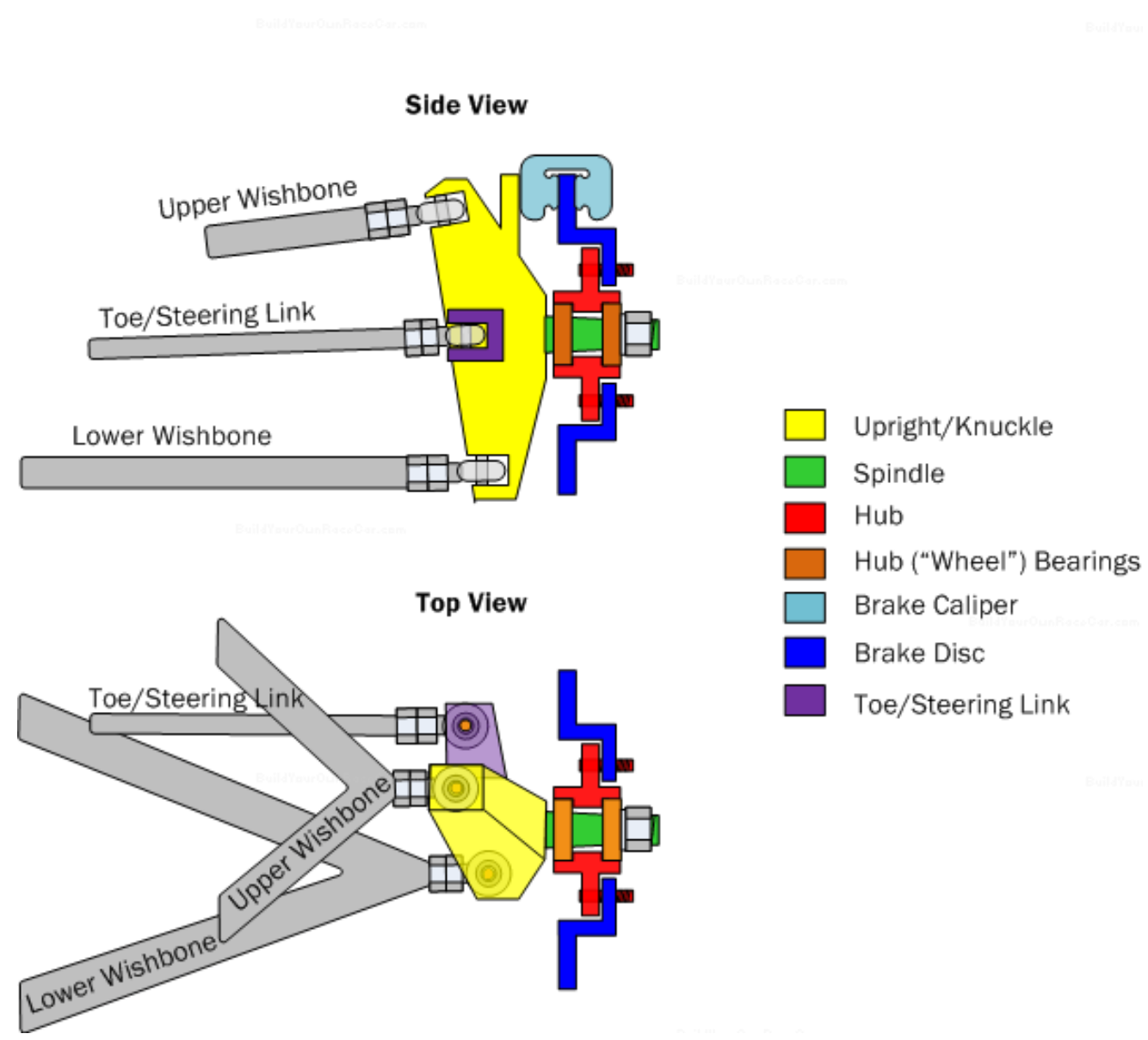

Fig.1 sideandtopviewofanuprightattachedtoawishbonesuspension [3]

Beforedesigningauprightweneedtoknowthefollowingsuspensionparameterswhicharebased onthe alignment ofa vehicle such as:

\section{Camberangle}

It is the angle measured between the wheel vertical alignment normal to its surface. If the wheelis perpendicular to its surface then its camber angle is 0 degrees. It is described as negative whentopofthewheelbeginstotiltinwardsthatmeanstowardsthevehiclewhereasthetiretilts 
outwards it is positive camber angle [4]. Most vehicle have neutral camber angles and most racecars have negative camber angle. Negative camber have more grip advantage during corneringthushavinggood handling whereasin neutral camber itresults in tire wear.

\section{NEGATIVE CAMBER}

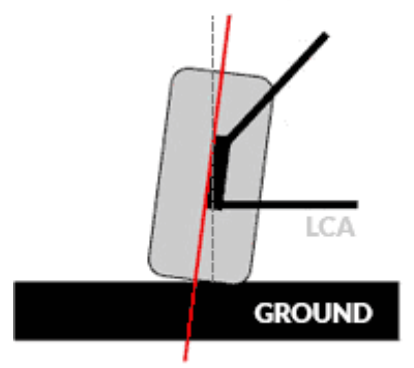

NEUTRAL CAMBER

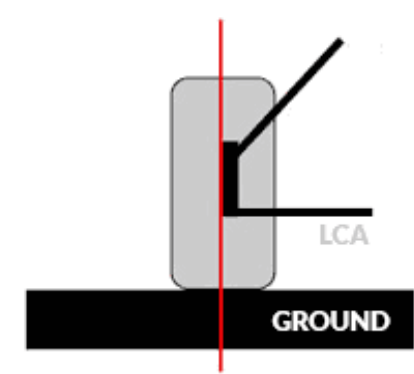

POSITIVE CAMBER

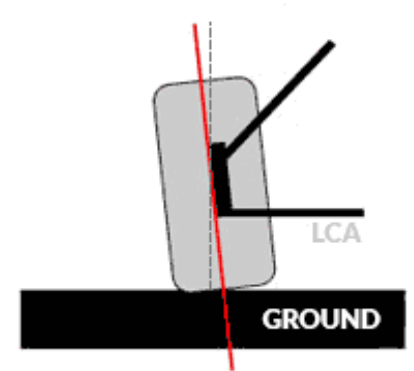

Figure.2Differentcamberangles[5]

\section{Casterangle}

4. It is the measure of angle between the steering axis and vertical axis from the side view asshown in fig.3. when both the axis are in same angle then it is neutral caster. when the top ofsteering angle moves forward it is negative angle and vice versa. most vehicles have positivecasterasitmakesstable at highspeeds and increases steeringstability [4].

\section{POSITIVE CASTER}

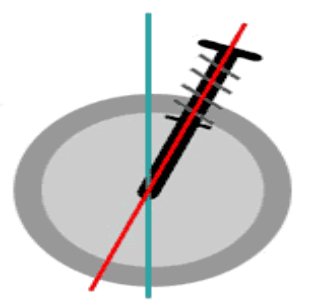

NEUTRAL CASTER

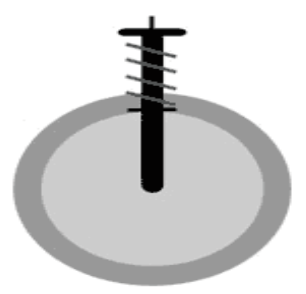

NEGATIVE CASTER

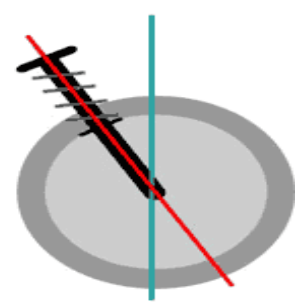

— - FRONT OF VEHICLE

Figure.3Differentcasterangles[5]

\section{Otherparameters}

The kingpin inclination is the line formed when joining the lower ball joint(LBJ) and upper balljoint(UPJ). It is used to determine the camber and caster angle based on the kingpin inclination[5]. The distance kingpin inclination is offset from the tire center line is called scrub radius asshownin Fig.4. 


\section{DESIGN AND ANALYSIS OF FORMULA SAE VEHICLE REAR UPRIGHT ANDCOMPARISION OF ANALYTICAL AND SOFTWARE ANALYSIS SOLUTIONS OFPRINCIPELSTRESSESAT DIFFERENTPOINTS}

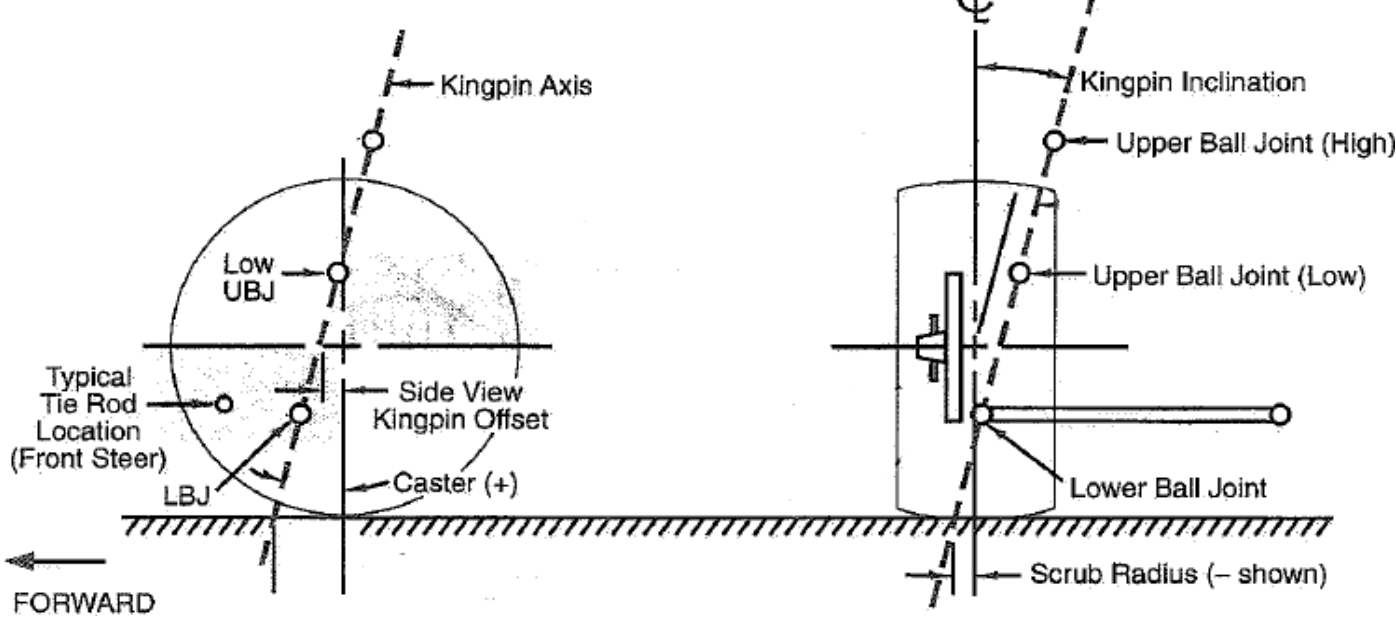

Figure.4Kingpininclinationandscrubradius[6]

\section{LITERATUREREVIEW}

The service life of an upright is based on its dynamic conditions like fatigue loads always applyon the upright during jounce and bounce. Longitudinal loads are applied when it is in static andlateral loads are being applied when during braking and centrifugal forces act during cornering ofvehicle[1].

Whiledoinganalysisweneedtotakeconsiderationofcamberandcasteranglewhichisconsidered as $6^{\circ}$ and then the loads are applied on it. Also the forces acted by wheel bearing isnot taken in to consideration while doing the analysis. The upright for doing static analysis isconsideredtherearoneasitis easetoconsider byeliminatingthe forcesactedbytheshaft [8].

Weight is one of the important consideration for a race car component mainly upright as it comesunder unsprung mass. So optimization of design is important and also the selection of materialwhich gives us the actual weight of the component whereas it should be rigid to withstand $1 / 4^{t h}$ ofcarssprungmassandthree timesgravityactingonitduringlongitudinal loading[9].

\section{DESIGNOFUPRIGHT}

\section{Designconsiderations}

We consider various parameters while designing a component. Irrespective of other details themajordesign parameters determinethe performanceofupright.

Theparametersthatareconsideredwhiledesigningtheuprightis:

1. Castoranglealongthe verticalaxisoftheuprightis $6^{\circ}$.

2. Itshouldhaveabrakecalipermountononesideoftheuprightandthesteeringrackmountshould be on theopposite side.

3. Boreshouldbeprovidedonthe topand bottomofupright toaccommodate theball joints.

4. Sufficientwallthicknesstomakethecomponentstrongandstifftowithstandtheweightofvehicle.

5. Lengthofuprightshould beconsideredas itshouldfitinthewheelhub.

6. Weightisanimportantparameterasithelpsforfueleconomyandgoodhandlingperformancesas well asmore acceleration.

In order to design a upright you have to consider all the suspension parameters such as wheeldimensions, the estimated weight of whole vehicle, track width, wheel base. This following dataistaken froma Formula hybrid vehicle team.
Wheelbase
68 in 
Trackwidth

\begin{tabular}{|ll|}
\hline Tires & $\mathrm{R} 1315565$ \\
\hline Massofvehicle & $470 \mathrm{~kg}$ \\
\hline Groundclearance & 2 in \\
\hline suspension & Doublewishbonedampertolowerwishbone \\
\hline
\end{tabular}

Table.1Suspensionparameters

\section{Materialselection}

After studying the comparison made in the table below an easy discussion can be made that AISI1018 is the suitable material as it is having better weight to strength ratio at a reasonable cost incomparisonto other materials.

\begin{tabular}{|c|c|c|c|c|c|c|}
\hline \multicolumn{2}{|r|}{ Materi } & \multirow{2}{*}{$\begin{array}{l}\text { Ultimatest } \\
\text { rength(MPa) }\end{array}$} & \multirow{2}{*}{$\begin{array}{c}\text { Yieldstre } \\
\text { ngth(MPa) }\end{array}$} & Density( & \multirow[t]{2}{*}{ Strengt } & \multirow{2}{*}{$\begin{array}{l}\text { Cost } / \mathrm{me} \\
\$\end{array}$} \\
\hline al & & & & $\mathrm{g} / \mathrm{cc}) \quad \mathrm{h}$ & & \\
\hline 18 & AISI10 & 350 & 340 & 7.87 & $55-60$ & 4.12 \\
\hline 20 & AISI10 & 380 & 370 & 7.87 & $60-62$ & 6.2 \\
\hline 30 & AISI41 & 410 & 400 & 7.85 & $70-75$ & 8 \\
\hline
\end{tabular}

Table.2Materialpropertiescomparison

\section{Forcesactingonanupright}

Longitudinalforceduringbraking.

While braking the weight on rear side tends to come to front side of the vehicle. So there is loadtransfertakes place fromrearto front.

Forceatthefrontside $=$ massattherearside $*$ acceleration

Lettherearsideofthevehiclebe 0.6 timesthetotalweight $=0.6 * 470=282 \mathrm{~kg}$

Forceisconsideredforworstcaseconditionsand4gloadsareappliedontheupright.Force $=282 * 4 * 9.8=110544.4 \mathrm{~N}$

Forceon 1 wheel $=110544.4 / 2=5527.2 \mathrm{~N}$

Lateralforces

Lateralforcesarebecauseof tworeasonscentrifugalforcesandlateral loadtransfer from outsidetoinside whileturning.

Turning radius $=3 \mathrm{mV}=30 \mathrm{kmph}=8.33 \mathrm{~m} / \mathrm{s}$

Centrifugalforce $=m v^{2} / r=\left(0.4 * 470 * 8.33^{2}\right) / 3=4348.37$ Lateralloadtransfer $=0.4 \times 470=188 \mathrm{~kg}$

Force $=188 * 3 * 9.8=5527.2 \mathrm{~N}$

lateralForceforonewheel $=2763.6 \mathrm{~N}$

Forceactingoncalipermounts $=$ torque $/$ radius $=58000 / 110=527.27 \mathrm{~N}$

\section{MODELING}

upright is modeled in Solid works 2015 software, which is used for designing, drafting and aswellasanalysisofdifferentcomponents.Itisdevelopedbydassaultsystems. Usingallthedesignconsiderationsand basedon thehybridformula rulesthis uprightisbeing modeled. 


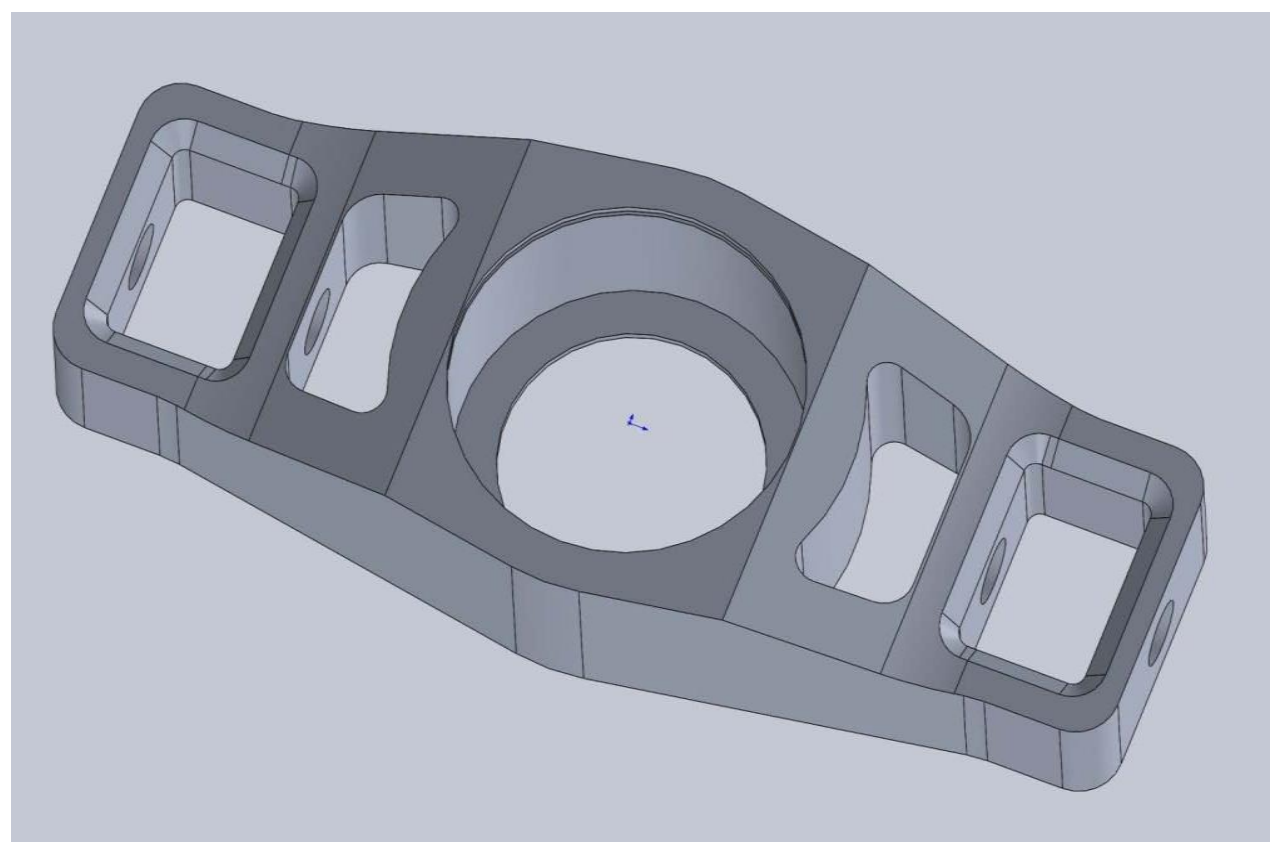

Figure.5Uprightdesignedusing Solidworks

As shown in figure.6 we can see the cross section area where the lateral and longitudinal forcesare applied. They are applied along the axis so while applying the forces the axis is being rotatedinAnsys and then the forces are applied. 


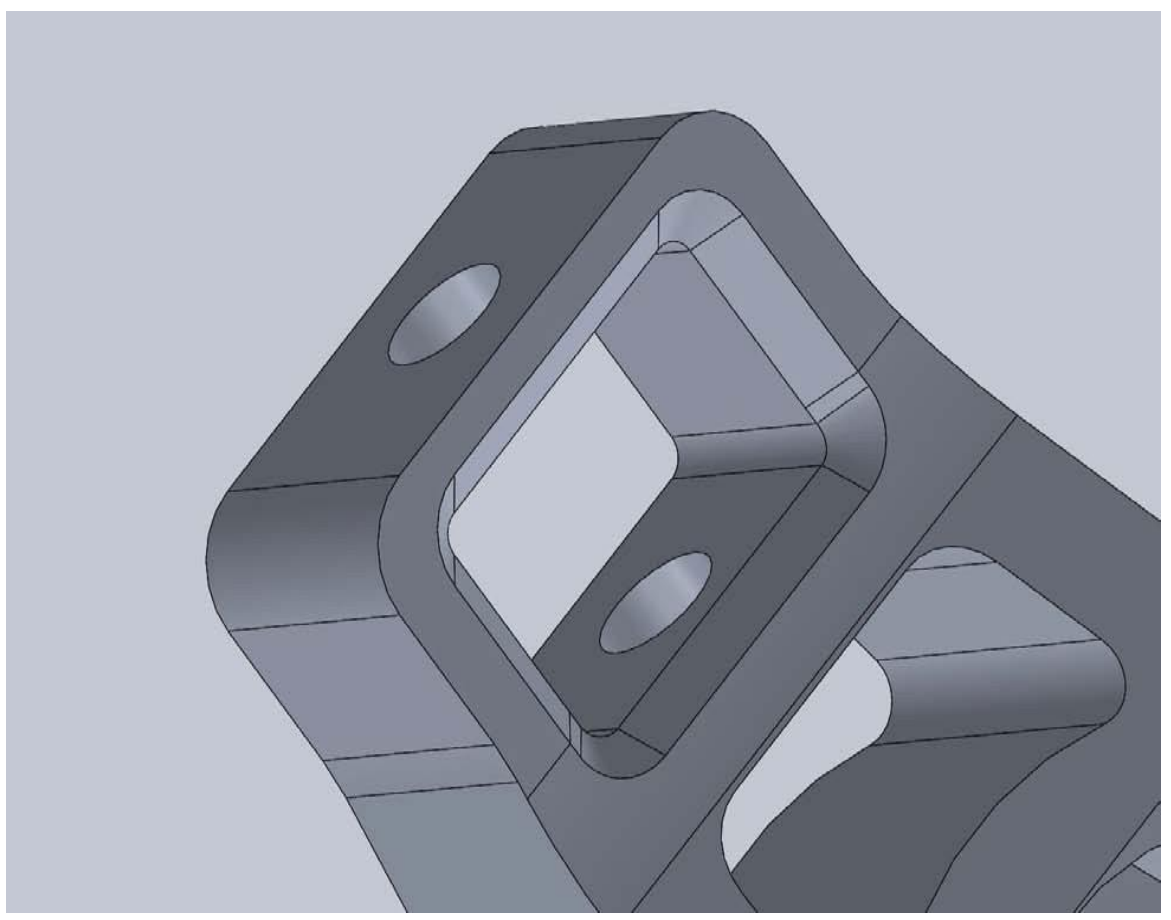

Figure.6Cross-sectionalarea

\section{THEORITICALCALCULATIONS}

Stress is a measure of external force acting on the cross sectional area of a component or body.Stress has a unit of $\mathrm{N} / \mathrm{m}^{2}$. There are two types of stress 1 .Normal stress - when force actsperpendicular to surface and other one is 2 . Shear force - when force acts parallel to surface of anobject.

$$
\begin{aligned}
& p \\
& \sigma=- \\
& A
\end{aligned}
$$

When we consider this equation there are lots of assumptions. They are - we assume all materialsare homogeneous, isotropic and elastic as well as object as prismatic meaning the cross-sectionwill be same along its length. Because of all these assumptions the object deforms uniformly atevery point along its cross-section. Normal stress at a point on a cross section is defined by(withsimilarequations inthey and $\mathrm{z}$ directions) [10].

$\underline{\Delta F} \underline{x}$ 


$$
x \Delta A \rightarrow 0 \Delta A
$$

Every small area is subjected to similar forces, and the sum of all the forces should be equal toresultant forces p. we integrate both sides of the equation and arrive at a relationship for normalstress.

$$
\int d F=\int_{A}
$$

$\sigma d A$

$\therefore p=\sigma A$

sowe usedthe above equationto findout $\sigma_{x}$ and $\sigma_{y}$ usingthe areaon which thestress actsupon.

$\sigma_{x}=3.83 \mathrm{MPa} \quad \sigma_{y}=2.87 \mathrm{MPa}$

\section{Findingprinciplestresses}

As the caster angle is applied so now the upright is rotated with $6^{\circ}$ and then we find the principlestresses and also the shear stress formed on upright using equation (1) and (2). These equationsarebeing solved using MATLAB.
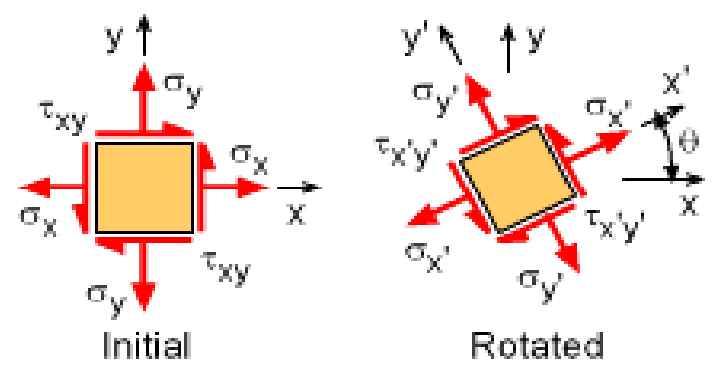

Figure.7Rotating stressestox-ycoordinatetox'-y'coordinatesystem[11]

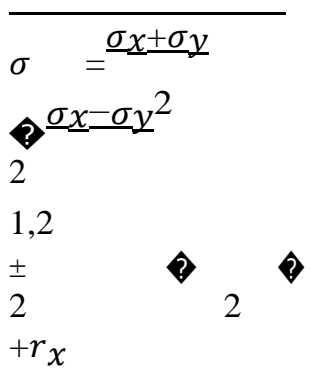

$\tan 2 \theta_{p}$

$=\underline{2 c} \underline{x y}$

$\sigma x-\sigma y$

(2) 


\section{STATICSTRUCTURALANALYSIS}

\section{ANSYS}

It is a simulation software package where it solve different governing equations to do the staticstructural analysis as well as other simulations. They solve these equations by dividing thecomponent to number of small parts this process is called meshing where as it is a finite elementanalysis. The results can be obtained in various formats. As we are not able to do structuralanalysis for complex structures with different kinds of loads applied on model so we use ansys todosimulations over thecomplex structures.

Stepstodoastructuralanalysis inansys:

1. Selectachosenmaterialfromtheengineering data.

2. Createageometryorimportigs.geometryfilefromsolidworks.

3. Weshoulddofinemesh togetaccurateresultsaftersimulation.

4. Aftermeshing,differenttypesofloadsarebeingappliedontheuprightandtheresultsarebeing obtaineda seen below.

The upright is rotated $6^{\circ}$ around the Z-axis as we need to find principle stresses when the casterangleis in $6^{\circ}$ angle. Thisis being donein ANSYS software setup.

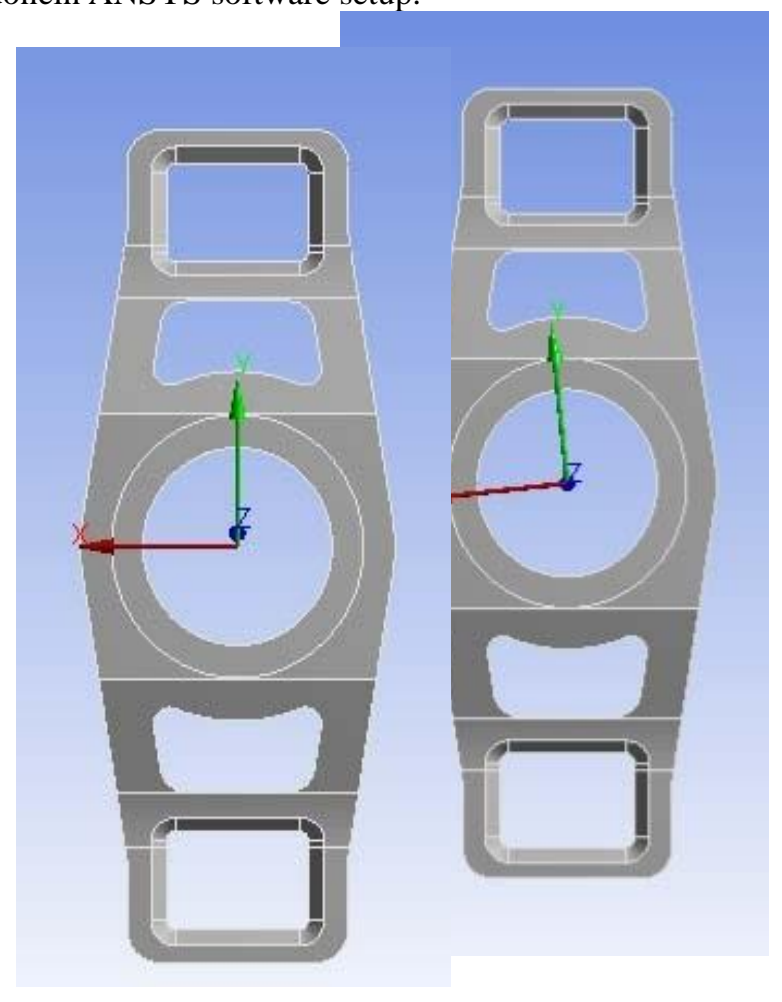

Figure.8RotationofaxisinAnsys 


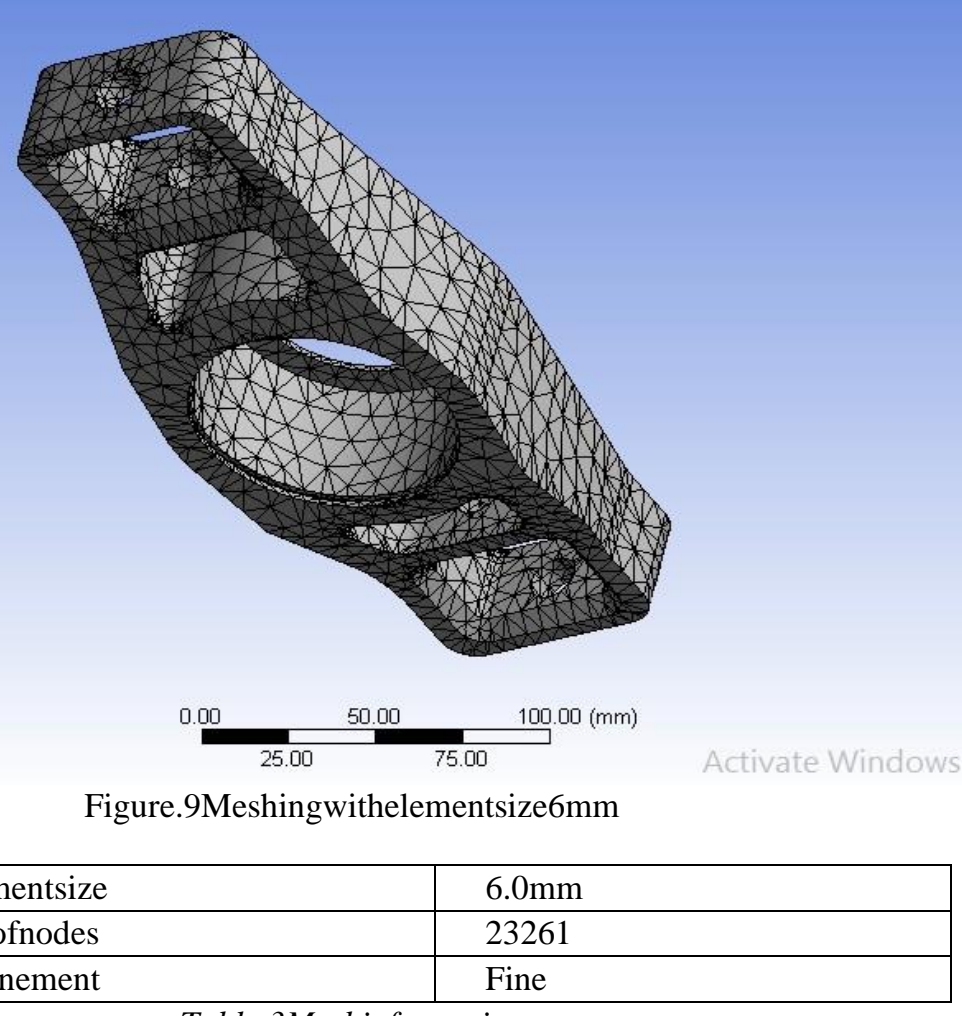

Table.3Meshinformation

Forcesappliedinlongitudinalandlateraldirections

A: Static Structural Fixed Support

Time: 1.5

06-Apr-19 8:33 PM

A Force: $5527 . \mathrm{N}$

B Force 2: 2763. N

C] Fixed Support

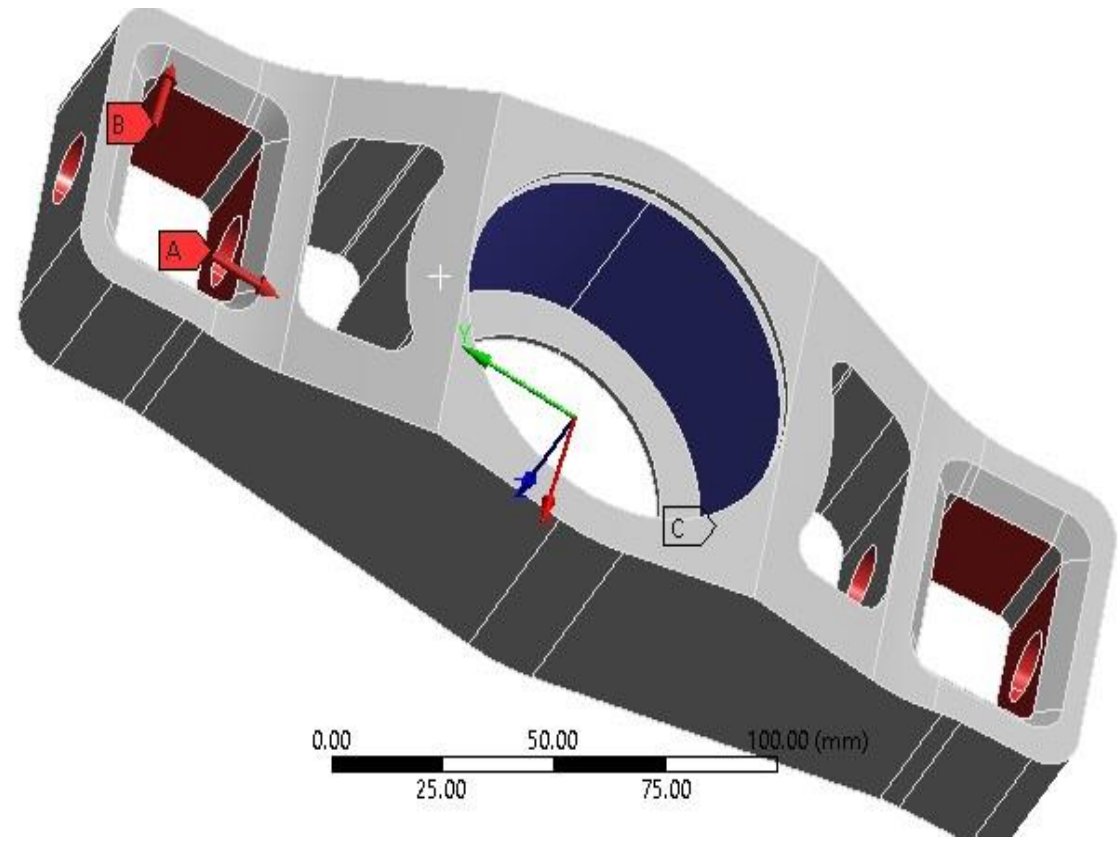

Figure.10Forcesappliedduringzerocasterangle

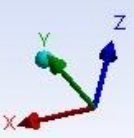

\section{.}

\begin{tabular}{|l|l|}
\hline Elementsize & $6.0 \mathrm{~mm}$ \\
\hline No.ofnodes & 23261 \\
\hline Refinement & Fine \\
\hline
\end{tabular}

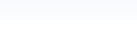

$$
\text { (1) }
$$




\section{A: Static Structural}

Fixed Support

Time: 1.s

06-Apr-19 7:36 PM

A Force: $5527 . \mathrm{N}$

B Force 2: 2763. N

C Fixed Support
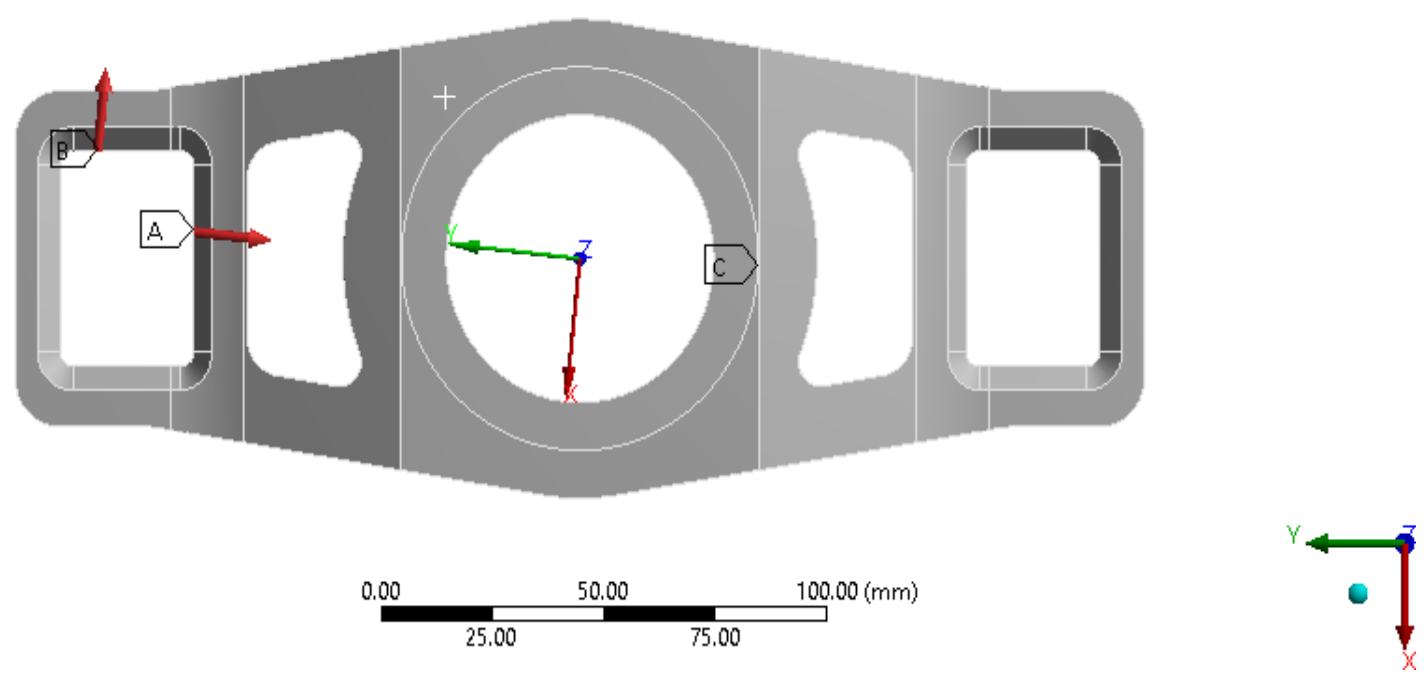

Figure.11 Forcesappliedduringpositivecasterangle(Afterrotation)

Totaldeformationatzerocaster

A: Static Structural Total Deformation

Type: Total Deformation

Unit: mm

Time: 1

06 -Apr-19 7:39 PM

0.0094789 Max
0.0084257
0.0073724
0.0063192
0.005266
0.0042128
0.0031596
0.0021064
0.0010532
0 Min

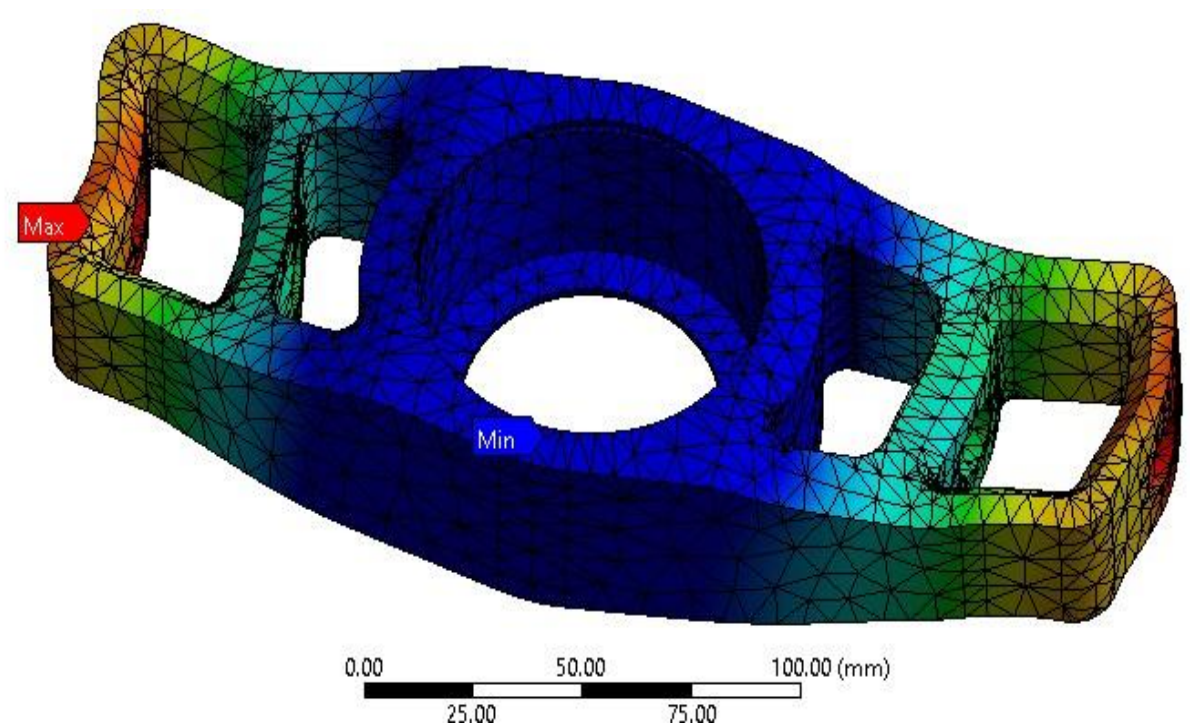

Figure.12Totaldeformationonupright 
Aftertherotationofaxisthroughthez-

axiswith $6^{\circ}$ theloadsarebeingappliedasseeninfigure.11. Wecanseethedecreaseofdeformationvaluewhencomparedtou prightatzerodegreeangleinfigure. 13 .

Totaldeformationatpositivecaster(Afterrotation)
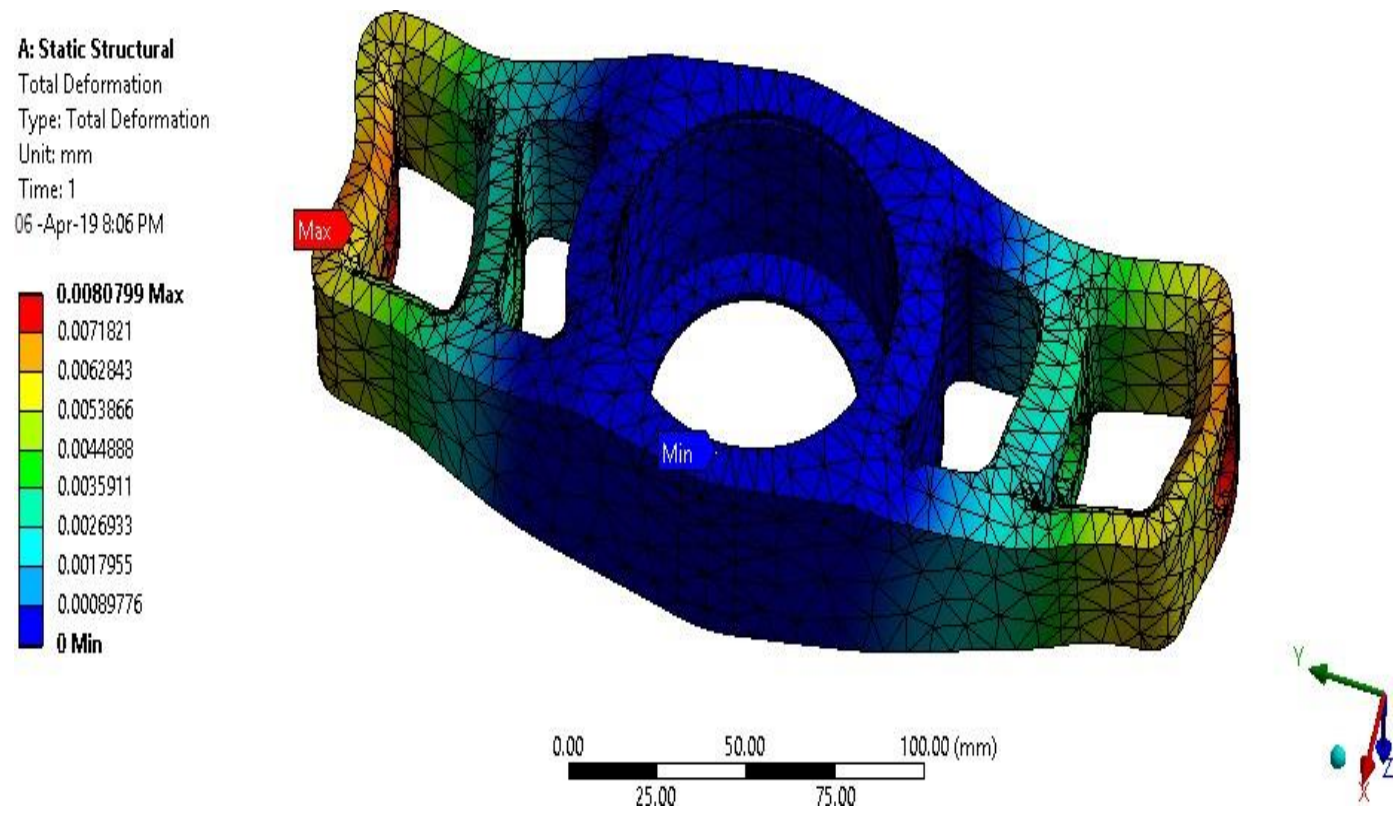

Figure.13Totaldeformationonupright

Stressdistributionatzerocaster

A: Static Structural

Equivalent Stress

Type: Equivalent (von-Mises) Stress Unit: $\mathrm{MPa}$

Time: 1

06-Apr-19 7:40 PM

\begin{tabular}{|l}
$31.108 \mathrm{Max}$ \\
27.655 \\
24.203 \\
20.751 \\
17.298 \\
13.846 \\
10.394 \\
6.9414 \\
3.489 \\
$0.036684 \mathrm{M}$
\end{tabular}

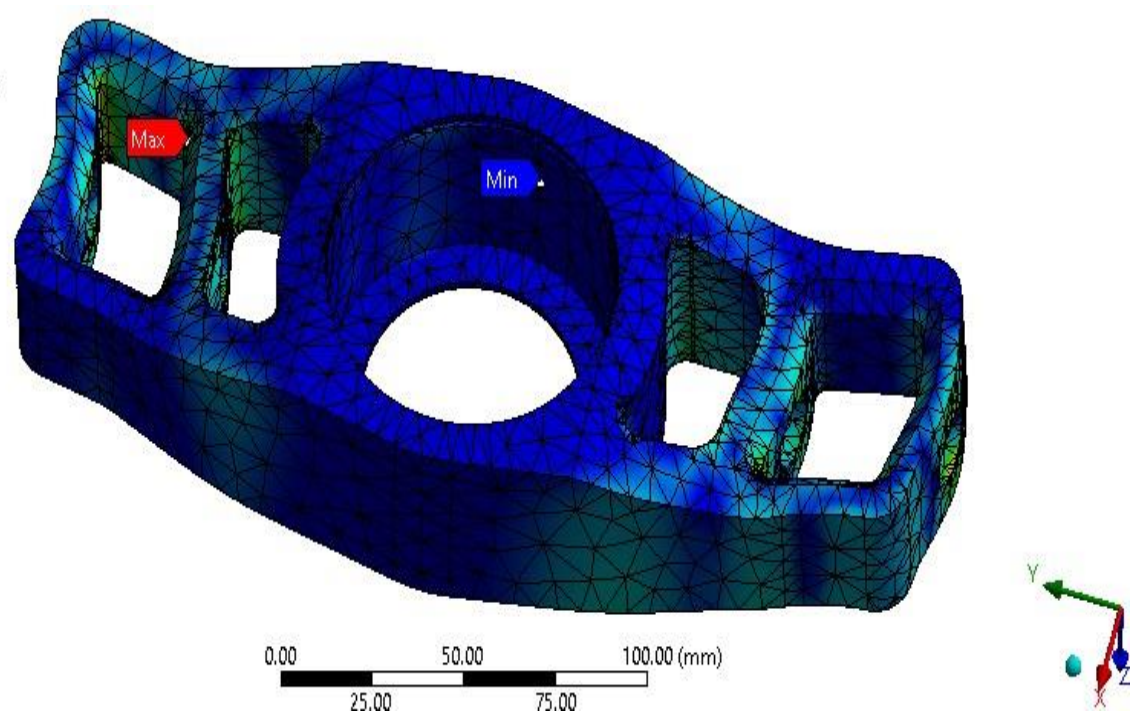

Figure.14Von-Misesstresses 
Stressdistributionatpositivecaster(Afterrotation)

A: Static Structural
Equivalent Stress
Type: Equivalent (von-h
Unit: MPa
Time: 1
O6-Apr-198:06 PM
\begin{tabular}{|l} 
\\
$27.714 \mathrm{Max}$ \\
24.638 \\
21.563 \\
18.488 \\
15.413 \\
12.337 \\
9.2621 \\
6.1868 \\
3.1116 \\
$0.036354 \mathrm{Min}$
\end{tabular}

Figure.15Von-Misesstresses
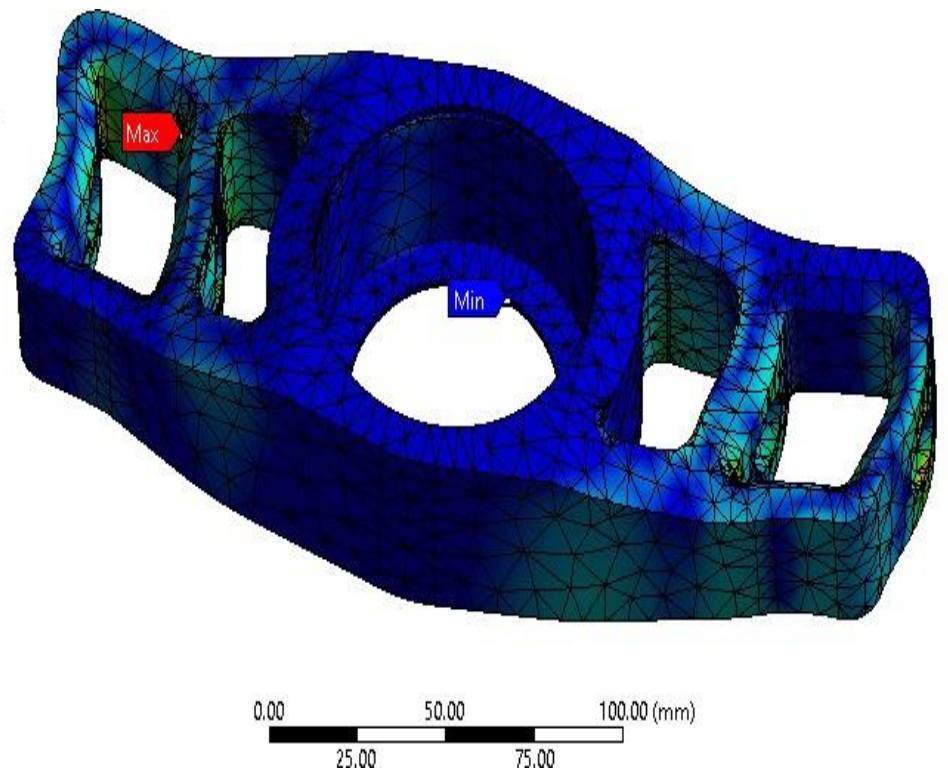

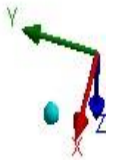

Findingfactorofsafety

Hereweareusingmaximumdistortionenergytheorytofindfactorofsafetyforchassis.According to this theory when the material is subjected to biaxial or triaxial stress it will fail onlyif maximum shape distortion energy is greater than shape distortion energy of specimen.(thistheoryis generally usedfor ductilematerials).

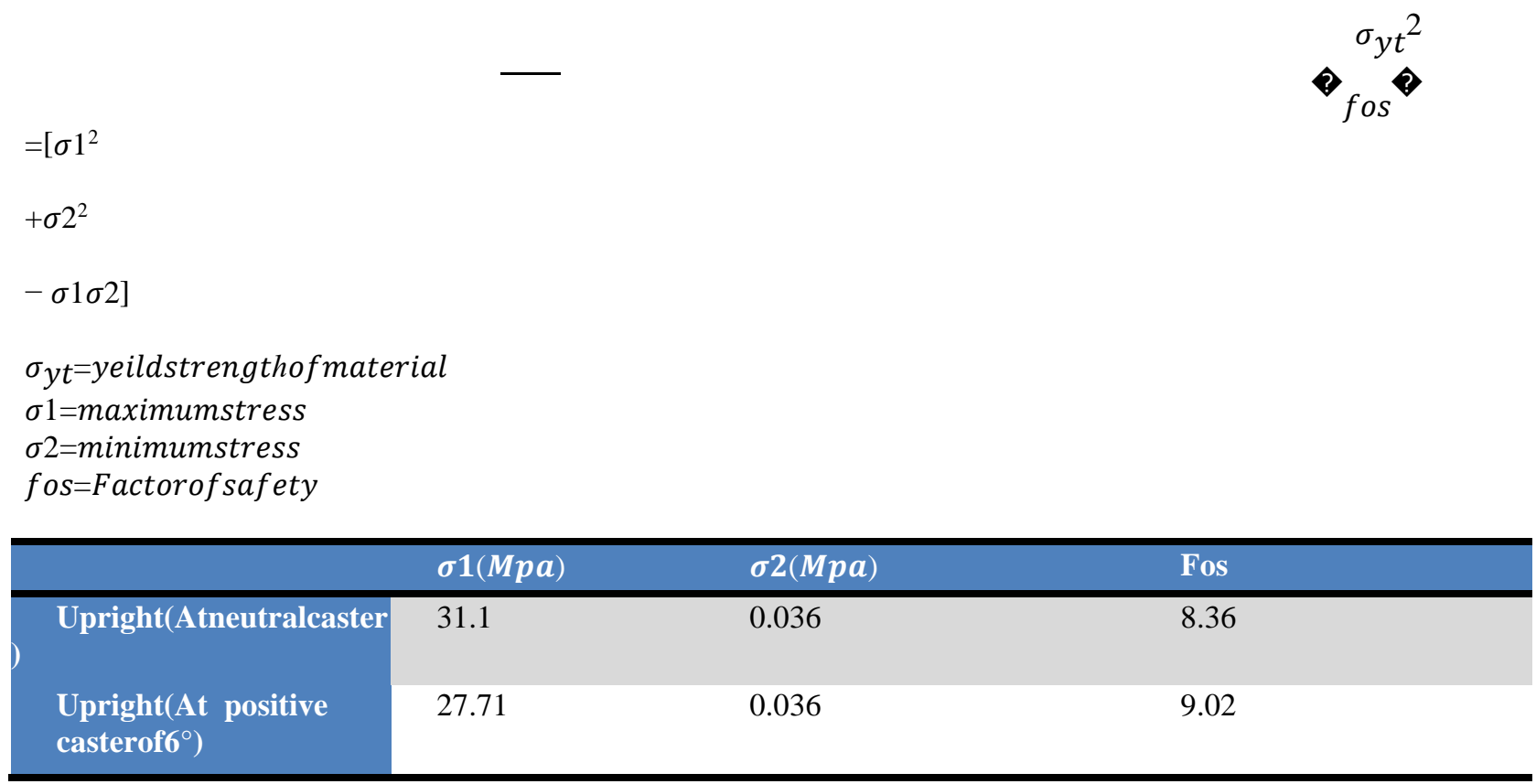

Table.4Factorofsafety 


\section{RESULTSANDDISCUSSION}

A: Static Structural

Equivalent Stress

Type: Equivalent (von-Mises) Stress

Unit: $\mathrm{MPa}$

Time: 1

07-Apr-19 12:28 AM

\begin{tabular}{|l|}
27.714 Max \\
24.638 \\
21.563 \\
18.488 \\
15.413 \\
12.337 \\
9.2621 \\
6.1868 \\
3.1116 \\
$\mathbf{0 . 0 3 6 3 5 4}$ Min
\end{tabular}

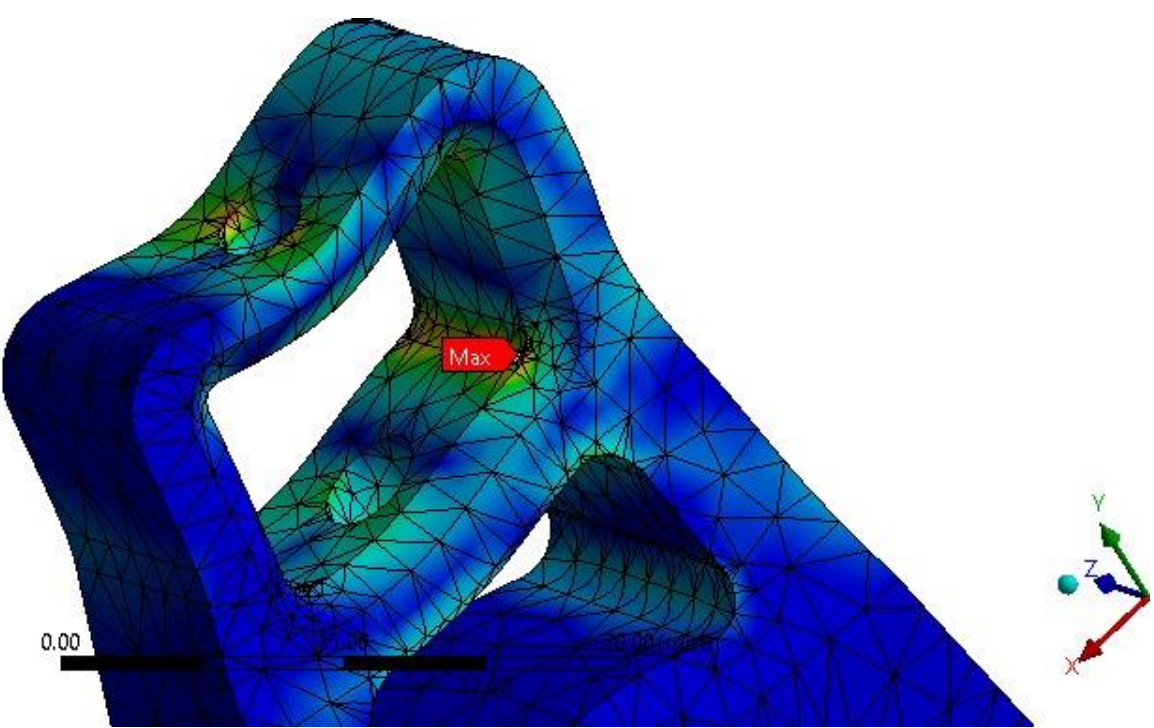

Figure.16Maxstressactingpoint

We can see the max stress acting at the corner where the area of longitudinal and lateral forces appliedareameet,asshowninfigure.16andalsowecanthemaximumstressdecreasewhenthetransformationof angle takes place as the shear stress is developed in the component. Whereas rest of the area ofcomponenthasafeasiblestresswhichisneartotheminimumstressobtainedinthestressvectorplot.

A: Static Structural
Equivalent Stress
Type: Equivalent (von-Mises) Stress
Unit: MPa
Time: 1
07 -Apr-191:49 AM
\begin{tabular}{|l}
27.714 Max \\
24.638 \\
21.563 \\
18.488 \\
15.413 \\
12.337 \\
9.2621 \\
6.1868 \\
3.1116 \\
0.036354 \\
\end{tabular}

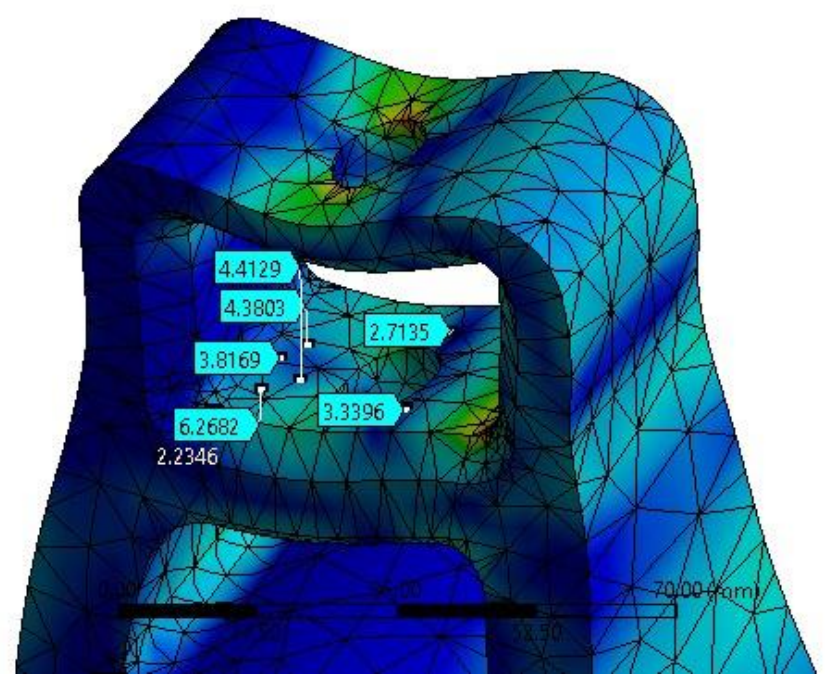

Figure.17Stressatdifferentpoints 


\begin{tabular}{|l|l|l|l|}
\hline Stresses atprobes(MPa) & LocationX & LocationY & LocationZ \\
& & & \\
\hline 3.8169 & 11.370683 & 82.519946 & 9.599767 \\
\hline 4.3803 & 9.629474 & 82.002066 & 13.350872 \\
\hline 6.2682 & 10.525925 & 82.763561 & 3.099029 \\
\hline 4.4129 & 7.047330 & 81.974359 & 6.932136 \\
\hline 2.7135 & -8.104269 & 82.389498 & 19.559983 \\
\hline 3.3396 & -8.104269 & 84.282837 & 2.133707 \\
\hline
\end{tabular}

\section{Table.4Coordinatesofprobepoints}

As the objective of the project is to compare analytical solution with analysis software solutionswecanobtainapproximateresults at the surfacewheretheforces is appliedbecauseof thereason we have obtained $\sigma_{x}=3.83$ and $\sigma_{y}=2.87$. Whereas the rest of the body they hasdifferent stresses at different points as the lateral and longitudinal forces are applied at certainareaofthe body and deforms non-uniformly.

Actually the comparison has few objections because the analytical calculations used to find theprinciple stresses are solved in 2D plane and are solved for infinitesimal element considering thesame deformation takes place over the whole body. Ansys gives result based on the governingequationssolved using finite elementmethod.

\section{REFERENCES}

1.
2. "eCOURSES,"
[Online].
Available: bin/ebook.cgi?topic=me\&chap_sec=07.2\&page=theory.

http://www.ecourses.ou.edu/cgi-

3. A. garg, "Fatigue Analysis and Optimization of Upright of a FSAE Vehicle," InternationalJournalof Science andResearch(IJSR), vol. 6, no.9, p. 6, 2017.

4. A. S. C. R. J. I. G. Gaurav Saxena, "Simulation and Optimization of wheel Hub and Uprightof Vehicle: A Review," IOSR Journal of Mechanical and Civil Engineering (IOSR-JMCE),vol. 14, no. 1, p. 6, 2017.

5. "Build your own race car," 2016. [Online]. Available:https://www.buildyourownracecar.com/race-carsuspension-basics-and-design/2/.

6. "YOSPEED," [Online]. Available: http://yospeed.com/wheel-alignment-explained-camber-caster-toe/.

7. "come and drive it," [Online]. Available:https://www.comeanddriveit.com/suspension/camber-castertoe.

8. Ó. K. Pétursson, "Uprights, wheel hubs and brake system for a new formul student racecar,"reykjavik university, 2016.

9. D.M. William.FMilliken,Racecarvehicledynamics,SAEinternational,1998. 
10. C.M.A.P. Z.S.J. W.WilliamKinkead,"DesignandOptimizationofaFormulaSAEVehicle,"Worcester Polytechnic Institute, 2010.

11. M.Azmeer,"DesignoptimizationofrearuprightsforUniMAPAutomotiveRacingTeamFormulaSAEracing car," JournalofPhysics,p. 6, 2015.

12. "Boston university ME," [Online]. Available: http://www.bu.edu/moss/mechanics-of-materials-sress/. 